Bond University

Research Repository

\title{
The effects of body armour on the power development and agility of police officers
}

Schram, Ben; Orr, Rob Marc; Hinton, Ben; Pope, Rodney; Norris, Geoff

\section{Published in: \\ Ergonomics}

DOI:

10.1080/00140139.2019.1648878

Licence:

Other

Link to output in Bond University research repository.

Recommended citation(APA):

Schram, B., Orr, R. M., Hinton, B., Pope, R., \& Norris, G. (2019). The effects of body armour on the power development and agility of police officers. Ergonomics, 62(10), 1349-1356.

https://doi.org/10.1080/00140139.2019.1648878

\footnotetext{
General rights

Copyright and moral rights for the publications made accessible in the public portal are retained by the authors and/or other copyright owners and it is a condition of accessing publications that users recognise and abide by the legal requirements associated with these rights.
}

For more information, or if you believe that this document breaches copyright, please contact the Bond University research repository coordinator. 


\section{Ergonomics}

\section{The Effects of Body Armour on the Power Development and Agility of Police Officers}

\section{Ben Schram, Robin Orr, Ben Hinton, Rodney Pope \& Geoff Norris}

To cite this article: Ben Schram, Robin Orr, Ben Hinton, Rodney Pope \& Geoff Norris (2019): The Effects of Body Armour on the Power Development and Agility of Police Officers, Ergonomics, DOI: 10.1080/00140139.2019.1648878

To link to this article: https://doi.org/10.1080/00140139.2019.1648878

Accepted author version posted online: 25 Jul 2019.

Submit your article to this journal

Џ Article views: 7

View Crossmark data ¿ 


\section{The Effects of Body Armour on the Power Development and Agility of}

\section{Police Officers.}

Ben Schram ${ }^{\mathrm{a} *}$, Robin Orr ${ }^{\mathrm{a}}$, Ben Hinton ${ }^{\mathrm{b}}$, Rodney Pope ${ }^{\mathrm{a}, \mathrm{c}}$ and Geoff Norris ${ }^{\mathrm{d}}$

${ }^{a}$ Tactical Research Unit, Bond University, Gold Coast, Australia $;{ }^{b}$ New South Wales

Police Force - Health and Fitness Unit, Sydney, Australia; ${ }^{c}$ School of Community

Health, Charles Sturt University, Albury, Australia, ${ }^{d}$ New South Wales Police Force -

Occupational Safety and Skills Command, Sydney, Australia.

bschram@bond.edu.au

Bond Institute of Health and Sport

Bond University

2 Promethean Way, Robina, 4229

$+61755955828$

Word Count: 3042 words 


\section{The Effects of Body Armour on the Power Development and Agility of Police Officers.}

A study was conducted in which 11 police officers wore one of three different types of Individual Light Armour Vests (ILAV), or normal station wear, for an entire day while completing power and agility-based tasks including a vertical jump (VJ), agility test, 20m sprint and counter movement jump (CMJ). Despite all three ILAVs being significantly $(\mathrm{p}<.05)$ heavier than normal station wear, there were no significant differences between any of the ILAVs in VJ, time to complete the agility test, $20 \mathrm{~m}$ sprint time, peak force, velocity, power and jump distance in the CMJ. There was a significantly $(p<.05)$ higher mean force produced in the CMJ while wearing all three ILAVs. The ILAV's investigated do not appear to be heavy enough to significantly affect the power or agility of police officers. The utilization of ILAVs by police officers does not appear to hinder policing tasks that involve agility or power development.

Keywords: law enforcement, load, personal protective equipment, occupational health and safety

\section{Practitioner Summary}

The addition of the extra load of military styled body armour is known to decrease performance and mobility. When compared to normal station wear, the wearing of three different ILAV types used in policing don't appear to be heavy enough to affect the power or agility of police officers. 


\section{Introduction:}

Individual Light Armour Vests (ILAVs) are increasingly being utilised by police forces to provide protection for officers from threats associated with daily tasks (Tomes, Orr, and Pope 2017; Schram, Hinton, et al. 2018). Any adoption of ILAVs for police officers will add to the current load which they are required to carry. These current loads can include communication equipment, handcuffs, pistol, ammunition, pepper spray and baton (Ramstrand et al. 2016) and weigh from $3.5 \mathrm{~kg}$ (Dempsey, Handcock, and Rehrer 2013) to over $20 \mathrm{~kg}$. Of concern, carriage of loads comprised of occupational equipment have been found to cause injuries and impact on the performance of their carriers (Knapik, Reynolds, and Harman 2004).

Across the wider tactical population, increases in load due to the wearing of protective armour by tactical personnel has been shown to alter gait patterns (Park et al. 2013), increase exposure time to enemy fire during fire and movement drills (Billing et al. 2015), decrease peak velocity and the ability to accelerate (Hunt et al. 2016) and decrease the ability of personnel to generate power from a standing start (Peoples et al. 2010). Previous research in police personnel has shown that increasing loads can increase ground reaction forces and time off balance (Dempsey, Handcock, and Rehrer 2014), decrease officer ability to accelerate (Dempsey, Handcock, and Rehrer 2013) and alter gait patterns (Ramstrand et al. 2016). These alterations in movement performance may detract from an officer's ability to conduct their duties safely and effectively such as when required to chase suspects or seek cover quickly. Likewise, any increase in load, ground reaction force or compromise to balance, may increase the associated injury risk (Dempsey, Handcock, and Rehrer 2014; Orr et al. 2015). 
Before any decisions are made regarding wider uptake of protective equipment in law enforcement departments, it is important to understand how the addition of extra load may affect policing, specifically any detrimental effect on performing occupational tasks (Schram, Orr, et al. 2018) or subjective criticisms from the users (Schram, Hinton, et al. 2018). Despite the plethora of information regarding heavy load carriage in the military and its effects on performance of occupational tasks (Billing et al. 2015; Hunt et al. 2016; Treloar and Billing 2011; Jaworski et al. 2015), those results should not be generalised either to the lighter loads of ILAVs, or to policing duties, as both loads and contexts are very different. Therefore, the aim of this investigation was to determine the effects of three different ILAVs on both the ability to generate power and the agility of police officers and to determine whether any observed differences were associated with particular ILAV types.

\section{Materials and Methods:}

A prospective, within-subjects, repeated measures design was employed and used a counterbalanced randomization procedure to determine which of three body armour types officers would wear, with each officer serving as their own control. On the first day Officers were randomly allocated, by lot draw, to one of the four conditions (N, ILAV A, ILAV B, ILAV C). On each subsequent day the Officer moved to the next of the four conditions from $\mathrm{N}$ to ILAV $\mathrm{C}$ in a loop so that they completed all conditions. A battery of occupationally relevant power and agility-based tasks were performed, with some performed both in the morning and in the afternoon, to enable assessment of the effects of fatigue. These occupationally relevant tasks were chosen as previous research has highlighted that the physical requirements of police officers may include relatively short periods of high intensity tasks including running, vaulting, dodging and jumping (Bonneau and Brown 1995; Collingwood, Hoffman, and Smith 2004). 
Assessments of physical competence in policing often use simulations such as a foot chase of an offender breaking the law which entails running and jumping (Strating et al. 2010). Each body armour type was worn for the duration of the day when performing occupational tasks and subsequently compared to what an officer would normally wear, classed as normal station wear $(\mathrm{N})$. The three armour types were provided as part of a tender process for the large-scale uptake of light armour systems for a state police department. Each armour system was designed to wear over a uniform, was all fully adjustable and was provided in a variety of sizes to fit the user comfortably. For security reasons, no other details or pictures could be provided of the armour systems. Station wear was the current equipment worn by officers which included duty belts, a radio, weapons and other necessary items (Baran et al. 2018).

\section{Subjects}

Eleven qualified officers of an Australian state police force (female $n=5$; male $n=6$ ), volunteered to be participants in this study. The officers involved were from various locations within the state police force and were currently active police members. To assist in translating the results of this research to the general population of the state police force, equal numbers of male and female officers were initially recruited, representing a variety of sizes, being small, medium or large with respect to body armour fit. Despite 12 officers initially being briefed about the study, one recruited female officer was unable to commence the research due to medical concerns. After the brief, all 11 participants formally consented to the study via a written consent form. Ethics approval for this study was granted by the Bond University Human Research Committee (Number 15803). The demographics of the 11 officer participants can be seen in Table 1. 
***Table 1 here***

\section{Procedures}

Data collection for the study was conducted at an Australian state police college from 29 AUG 2016 to 02 SEPT 2016. The ambient temperature and relative humidity across the testing times ranged from 12 to $24^{\circ} \mathrm{C}$ and from 36 to $93 \%$, respectively, giving a heat stress index varying between 11.4 and $22.6^{\circ} \mathrm{C}$ while testing occurred.

The same sequential order of events was utilized each day at the same time to minimize any diurnal variation. The daily schedule can be seen in Table 2 . As this study was part of a larger program of research involving many activities, only those applicable to this study are included. The activities included a vertical jump performed both in the morning and afternoon, an agility test, $20 \mathrm{~m}$ sprint and counter movement jump. Each of the activities are explained in more detail below. The officers kept their designated ILAV on for the duration of the day.

$* * *$ Table 2 here***

\section{Vertical Jump}

Vertical jump height of officers was determined using a Vertec ${ }^{\mathrm{TM}}$ apparatus (Vertec Scientific Ltd., Aldermaston, UK). After determining the standing upward reach height for each officer, they were instructed to perform a rapid countermovement jump with an arm swing jump as high as possible and to displace the horizontal plastic fins on the device. The best of two attempts was taken and maximal jump height was recorded to the nearest $\mathrm{cm}$. The vertical jump is a valid measure of leg power (Nindl et al. 2007) and has been associated with injury and illness risk in this population (Orr et al. 2016). 


\section{Illinois Agility Test}

The Illinois Agility test was used to determine the officer's agility. It has been shown to be a valid measure of agility which assesses movement in different planes (Raya et al. 2013). Officers were instructed to lie in a prone position behind the start line with their fingers placed underneath their foreheads. On the verbal command 'go' officers got to their feet as quickly as possible and ran around the permanent, premarked, course as fast as possible. Course time was measured by two assessors using stopwatches (Jadco, Stopwatch, Victoria, Australia) with the mean time taken as the result. Time was recorded to the nearest $1 / 10$ of a second.

\section{0m Sprint}

A 20-meter sprint was assessed on a track which was marked out with a light gate at both the start and finish of the track, spaced $20 \mathrm{~m}$ apart as measured by a digital mini-measuring wheel (Senshin Industry Co., Ltd. Osaka: Japan). Officers were permitted to use a self-selected start position and started with an initial untimed practice run at approximately $80 \%$ of their maximum capacity. Officers began the sprint in their own time and passing the first timing gate began the timer for the scenario. Time was recorded to the nearest $1 / 10$ of a second.

\section{Countermovement Jump}

Countermovement jump forces were measured using the Fitness Technology Force Platform and Ballistic Measurement System software. All officers were instructed to step on the platform, and when ready, perform a countermovement jump as high as possible. To limit any involvement of the upper body and potential impacts of the body armour on performance, arms were held across the chest and all movement was performed by the lower body. One countermovement jump was performed unless 
officers lost balance and fell off the force platform. Data were collected using Ballistic Measurement Systems (Innervations Pty Ltd, Victoria, Australia) software and included mean and peak force, velocity, and rate of force development.

\section{Statistical Analyses}

All recorded data except for data relating to ambient weather conditions and subjective evaluations of ILAV were entered into a data spreadsheet in SPSS version 23 (IBM 2015) and were then cleaned for analysis before additional variables, such as change scores and means of morning and afternoon measurements, were calculated for each participant and added to the data set. Initial descriptive analyses were then conducted to provide counts, means, standard deviations and ranges for the included variables, as relevant depending on levels of measurement. These descriptive statistics were derived for each sex and for each body armour type, where relevant, as well as for the entire sample. A summary of the demographic and key anthropometric data for the participants has been provided in Table 1.

Following these descriptive analyses, independent samples $t$ tests were performed to determine differences in results by sex and a repeated measures analyses of variance (ANOVA) were conducted to examine the effects of body armour type on key performance measures, with post hoc pairwise comparisons using a Bonferroni adjustment. Alpha was set at $P<0.05$, a priori.

Data relating to ambient weather conditions were analysed descriptively to determine the range of ambient temperatures, levels of relative humidity and range of heat stress index scores observed during data collection times on the four data collection days. These have been reported in the Methods section of this report. 


\section{Results}

The weights of each ILAV type can be seen in Table 3. There were significant differences between mean weights of all three ILAV types $(\mathrm{p}<.050$ for all on Bonferroni post-hoc tests). The minimum and maximum weights are reflective of the small and large sizes of each ILAV with ILAV A ranging from $3.52-5.50 \mathrm{~kg}$, ILAV B ranging from $2.90-4.82 \mathrm{~kg}$ and ILAV C from $2.54-4.04 \mathrm{~kg}$. When expressed relative to body weight, the average weights were $5.55 \pm 0.77 \%, 4.72 \pm 0.56 \%$ and $4.37 \pm 0.61 \%$ body weight for ILAV A, ILAV B and ILAV C respectively. There were no significant differences in the ILAV weights when expressed as relative body weight between males and females (ILAV A male $5.40 \pm 0.70 \mathrm{~kg}$ vs female $5.75 \pm 0.89 \mathrm{~kg}$, ILAV B male $4.63 \pm 0.47 \mathrm{~kg}$ vs female $4.82 \pm 0.70 \mathrm{~kg}$, ILAV C male $4.29 \pm 0.57 \mathrm{~kg}$ vs female $4.47 \pm 0.71 \mathrm{~kg}$ ). The duty loads of each ILAV condition, which included standard appointments (radio, handcuffs etc), was significantly heavier $(\mathrm{p}<0.001)$ than the standard appointments alone which weighed on average $8.69 \pm 0.68 \mathrm{~kg}$. The fully-loaded weights of officers while the duty loads did not differ significantly by ILAV type or between ILAVs and normal station wear $(\mathrm{N})$.

*** Table 3 here***

The results of all assessments by ILAV type can be seen in Table 4 with all participants reported as a group. Table 5 separates the participants into sex. There were no significant differences in AM vertical jump heights $(\mathrm{F}[3,30]=2.417, \mathrm{p}=.0 .86)$ or $\mathrm{PM}$ jump heights $(\mathrm{F}[3,30]=0.555, \mathrm{p}=0.649)$ between any of the ILAV or $\mathrm{N}$ conditions and as expected, normal station wear resulted in the highest relative vertical jump height, at $34.55 \pm 7.24 \mathrm{~cm}$ in the AM and $36.91 \pm 8.34 \mathrm{~cm}$ in the PM. Vertical jump height increased 
in the afternoon session (by approx. $2 \mathrm{~cm}$ ) for all body armour types, with this increase reaching statistical significance for ILAV B only $(\mathrm{t}[10]=1.936, \mathrm{p}=.002)$. Males jumped higher than the females in all conditions at both times except for the PM N condition.

There were no significant differences in times to complete the Illinois agility test between the load conditions $(F[1.604,16.043]=0.835, p=.428)$, with the quickest average time recorded while wearing ILAV C with $20.61 \pm 2.04 \mathrm{sec}$. The females were significantly slower than the males to complete the agility test $(\mathrm{p}<.05)$, however there were no differences between any load condition for males or females.

In a similar manner, there were no significant differences in times for the group to complete the $20 \mathrm{~m}$ sprint task between any of the load conditions $(\mathrm{F}[3,30]=0.224$, $\mathrm{p}=.879$ ). Males completed the $20 \mathrm{~m}$ sprint task significantly faster whilst wearing ILAV $\mathrm{C}(\mathrm{F}[3,15]=3.794, \mathrm{p}=0.033)$ and were significantly faster $(\mathrm{p}<.05)$ than females in all load conditions except ILAV B ( $\mathrm{p}=.123)$.

Body armour type did significantly affect the mean force produced by the group during the countermovement jump task $(\mathrm{F}[3,30]=40.998, \mathrm{p}<.001)$. Wearing any of the three types of body armour resulted in significantly higher (2.3-3.2\% higher) mean forces during the jump than wearing normal station wear $(840 \pm 197 \mathrm{~N}, \mathrm{p}<.001$ in each comparison) but differences between ILAV A, ILAV B and ILAV C in associated mean force production during the countermovement jump were minimal and did not reach significance. The same was seen for males with significantly greater mean force with ILAV A, ILAV B and ILAV C than normal station wear $(F[3,15]=20.030, p<.001)$ and 
for females but with ILAV A and ILAV B being associated with more mean force production than ILAV C and normal station wear.

Peak forces generated during the countermovement jump were variable across officer participants regardless of body armour type and not significantly affected by body armour type $(F[3,30]=0.186, p=.905)$. Similarly, peak jump distance $(F[3,30]=$ $0.697, \mathrm{p}=.561)$, peak velocity $(\mathrm{F}[3,30]=0.397, \mathrm{p}=.756)$ and peak power $(\mathrm{F}[3,30]=$ $0.204, p=.893$ ) achieved during the countermovement jump were not significantly affected by body armour type. There were also no differences between males and females in peak force, peak jump height, peak velocity or peak power in the counter movement jump. When compared to males, females produced less peak force and peak velocity while wearing ILAV B, less peak force, peak power and peak jump height while wearing ILAV C and less peak power when wearing normal station wear.

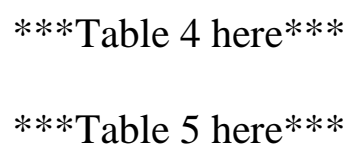

\section{Discussion:}

The aim of this investigation was to determine whether wearing any one of a variety of ILAVs would significantly affect the ability of police officers to develop power and whether it would impact on their agility. The results of this study suggest that the small relative loads constituted by these particular body armour systems do not appear to be heavy enough to affect most power or agility-based tasks for police officers any more than wearing current station wear. However, despite their relatively light addition of load, these ILAV may increase the mean forces associated with some tasks, such as jumping, particularly those requiring rapid movements and acceleration. 
Similar to findings of previous research (Dempsey, Handcock, and Rehrer 2014), in the current study vertical jump performance was found to be reduced when the officers wore body armour (approximately 2-5\% less jump height achieved). Although these observed reductions in jump height did not reach statistical significance, this may be due to the smaller sample size in the current study of 11 when compared to the 52 in the study by Dempsey et al (Dempsey, Handcock, and Rehrer 2014). In addition, the lighter loads in this study of $2.45-5.50 \mathrm{~kg}$ are less than the mean load of $7.65 \mathrm{~kg}$ in the study by Dempsey et al (Dempsey, Handcock, and Rehrer 2014). However, the trend in results is nevertheless consistent with a reduction in vertical jump (VJ) height when wearing body armour. It should be noted that there were no significant differences between the different types of ILAV in their impacts on VJ height, with a similar reduction in jump height observed across all three ILAV variants when compared to normal station wear.

Considering the possibility of fatigue from wearing body armour, it could be expected that if significant fatigue was occurring in officers due to wearing body armour throughout whole days, then physical task performance scores would be worse in the afternoon than in the morning. There was however a slight increase observed in vertical jump height in the afternoon when compared to the morning in the current study, possibly indicating a learning effect. With this finding considered, it does not appear that the ILAVs investigated in this study fatigued the officers enough to impact their performance of tasks throughout the day.

There were also no significant differences between any of the ILAV and normal station wear conditions in performance on the agility test or $20 \mathrm{~m}$ sprint in this study. 
There is currently minimal literature through which comparisons can be made to these findings. In a study by Carlton et al. (2014) officers performing a 10m sprint followed by a $10 \mathrm{~m}$ victim drag were found to be significantly slower when wearing load, whereas in this study no significant differences were found in completion times. Again, there were notable differences in the loads being compared, with the loads carried by officers in the study of Carlton et al. (2014) weighing over $20 \mathrm{~kg}$ and being compared to an unloaded condition of police fatigue-styled clothing and weapon only, whereas the relative difference in loads imparted by the ILAVs above that of station wear alone may not have been enough to solicit a significant change in task completion times.

The effect that body armour was observed to have on force production capability in this study may be magnified if heavier loads were carried. Investigations with military personnel carrying external loads of around 10-30kg (Billing et al. 2015) have found that the loads carried negatively affected carriers' abilities to accelerate from a prone position. In another study (Jaworski et al. 2015), sprint split times were significantly slowed by 5.7 seconds when carrying loads of $15 \%$ body weight over distances of 75yards. In an attempt to quantify the negative impacts of load on soldier mobility, Hunt et al. (2016) postulated that external loads reduced soldier speed during 'break contact' drills and 'fire and movement' drills by roughly $0.8 \%$ per kg and $1.1 \%$ per kg of added load, respectively. While those loads are notably heavier than the additional loads carried in this study, it is important to acknowledge that there will be a decrease in the ability to generate power associated with any adding of load to police officers. 
Overall, it appears that wearing of ILAVs has minimal effects on the ability of police officers to generate power and the agility of police officers, when compared to wearing normal station wear. This may be because the change in total load weight imparted by these particular ILAVs is relatively small when compared to the differences imparted by the heavier military loads as discussed in previous studies (Orr, Schram, and Pope 2018). Military styled body armour, being up to three times heavier than law enforcement body armour, can slow time to complete agility courses and short sprints (Orr, Schram, and Pope 2018). The long-term effects of using ILAVs for police officers are still unclear at this stage and may be an avenue for future research to ensure the minimization of injury risks and to maximise the operational capability of police officers while ensuring adequate protection from threats.

Peak forces affecting the musculoskeletal system may be higher during explosive movements such as the counter movement jump when officers are wearing body armour than when they are wearing normal station wear, and it is possible this might increase injury risk for the lower limb. Wearing heavier, military styled body armour (6.4-10.8kg), has been shown to increase ground reaction forces, time to complete tasks, increase trunk flexion and decrease trunk rotation (Phillips, Shapiro, and Bazrgari 2016; Lenton et al. 2016). As with military personnel, strength training along with education and training on landing techniques when wearing loads may be of benefit to police officers required to wear ILAVs.

Further research should examine the effects of wearing these ILAVs over a longer period of time. Apart from potential differences in ability to generate power, there may be an increase in lower limb injury risk with any increases in loading 
imparted by the addition of the ILAV. The increases in mean forces observed during the CMJ in this study, with all three types of armour, although small (2-3\%), might expose those with poor mechanics, a history of previous injury or neuromuscular deficits to an increased risk of injury (Dempsey, Handcock, and Rehrer 2014). The small relative increase in load associated with wearing ILAVs may have more of an impact when the wearing is sustained, chronically, and may lead to knee and lower limb injuries due to an early increase in fatigue (Sell et al. 2010; Knapik 2014). To mitigate this risk, recommendations have been made for military personnel tasked with load carriage to receive both targeted strength training and education and training on landing technique (Sell et al. 2010).

Despite no significant effects being found on the power development and agility of police officers while wearing these ILAV's, there are further questions which need to be answered prior to any uptake of such systems. Ensuring user comfort and acceptance is important and ensuring specific occupational tasks associated with policing are not hindered by the use of such additional loads is also essential. Investigation of the individual effects of wearing the ILAVs on posture and mobility, with their potential relationships to risk of injury is also an important next step in research in this area.

There are some limitations to this study which need to be acknowledged. While all efforts were made to create a battery of occupational relevant assessments for police officers, there is a difficulty in catering to the diverse role which policing entails. The assessments conducted in this study therefore may not be representative of all situations or tasking which a police officer is required to do and may not highlight the full hinderance to occupational mobility which wearing an ILAV represents. 


\section{Conclusion}

Overall, it appears that lighter ILAV's, which are specifically designed for use in policing, do not appear to be heavy enough to decrease the ability for an officer to be agile or to generate power when compared to normal station wear. However, the longterm effects of wearing these occupational loads are unclear. Finding a balance of optimal protection for officers while concurrently not hindering performance is vital in this occupation

\section{Acknowledgements}

The authors would like to thank the members of the NSW State Police who assisted in this research project along with Doctor of Physiotherapy students, Darren Corea and Kate Lyons, for their assistance with data collection.

\section{Disclosure Statement}

This study was commissioned and funded by the New South Wales Police Force. The authors report no conflict of interest.

\section{References}

Baran, K., J. Dulla, R. Orr, J. Dawes, and R. Pope. 2018. "Duty loads carried by the LA sheriff's department deputies." Journal of Australian Strength \& Conditioning 26:34-8.

Billing, D. C., A. J. Silk, P. J. Tofari, and A. P. Hunt. 2015. "Effects of Military Load Carriage on Susceptibility to Enemy Fire During Tactical Combat Movements." Journal of Strength and Conditioning Research 29 Suppl 11:S134-8. doi: 10.1519/jsc.0000000000001036.

Bonneau, J., and J. Brown. 1995. "Physical ability, fitness and police work." Journal of Clinical Forensic Medicine 2 (3):157-64. doi: 10.1016/1353-1131(95)90085-3.

Carlton, S. D., P. D. Carbone, M. Stierli, and R. M. Orr. 2014. "The Impact of Occupational Load Carriage on the Mobility of the Tactical Police Officer." Journal of Australian Strength \& Conditioning 22 (1):32-7.

Collingwood, T., R. Hoffman, and J. Smith. 2004. "Underlying physical fitness factors for performing police officer physical tasks." Police Chief 71:32-7.

Dempsey, P. C., P. J. Handcock, and N. J. Rehrer. 2013. "Impact of Police Body Armour and Equipment on Mobility." Applied Ergonomics 44 (6):957-61. doi: 10.1016/j.apergo.2013.02.011. 
Dempsey, P. C., P. J. Handcock, and N. J. Rehrer. 2014. "Body Armour: the Effect of Load, Exercise and Distraction on Landing Forces." Journal of Sports Sciences 32 (4):301-6. doi: 10.1080/02640414.2013.823226.

Hunt, A. P., P. J. Tofari, D. C. Billing, and A. J. Silk. 2016. "Tactical Combat Movements: Inter-individual Variation in Performance due to the Effects of Load Carriage." Ergonomics:1-10. doi: 10.1080/00140139.2015.1132780.

Jaworski, R., A. Jensen, B. Niederberger, R. Congalton, and K. Kelly. 2015. "Changes in Combat Task Performance Under Increasing Loads in Active Duty Marines." Military Medicine 180 (3):179-86. doi: 10.7205/MILMED-D-14-00432.

Knapik, J. J. 2014. "Injuries and injury prevention during foot marching." Journal of Special Operations Medicine : a peer reviewed journal for SOF medical professionals 14 (4):131-5.

Knapik, J. J., K. L. Reynolds, and E. Harman. 2004. "Soldier load carriage: historical, physiological, biomechanical, and medical aspects." Military Medicine 169 (1):45-56.

Lenton, G., B. Aisbett, D. Neesham-Smith, A. Carvajal, and K. Netto. 2016. "The effects of military body armour on trunk and hip kinematics during performance of manual handling tasks (.)." Ergonomics 59 (6):806-12. doi: 10.1080/00140139.2015.1092589.

Nindl, B. C., B. R. Barnes, J. A. Alemany, P. N. Frykman, R. L. Shippee, and K. E. Friedl. 2007. "Physiological consequences of US Army Ranger training." Medicine and Science in Sports and Exercise 39 (8):1380-7.

Orr, R., V. Johnston, J. Coyle, and R. Pope. 2015. "Reported Load Carriage Injuries of the Australian Army Soldier." Journal of Occupational Rehabilitation 25 (2):316-22. doi: 10.1007/s10926-014-9540-7

Orr, R., R. Pope, S. Peterson, B. Hinton, and M. Stierli. 2016. "Leg power as an indicator for risk of injury or illness in police recruits." International Journal of Environmental Research and Public Health 13 (2):237-47.

Orr, R., B. Schram, and R. Pope. 2018. "A comparison of military and law enforcement body armour." International Journal of Environmental Research and Public Health 15 (2). doi: 10.3390/ijerph15020339.

Park, H., D. Branson, A. Petrova, S. Peksoz, B. Jacobson, A. Warren, C. Goad, and P. Kamenidis. 2013. "Impact of ballistic body armour and load carriage on walking patterns and perceived comfort." Ergonomics 56 (7):1167-79. doi: 10.1080/00140139.2013.791377.

Peoples, G., A. Silk, S. Notley, L. Holland, and B. Collier. 2010. "The effect of a tiered body armour system on soldier physical mobility." University of Woolongong, Australia.

Phillips, M. P., R. Shapiro, and B. Bazrgari. 2016. "The effects of military body armour on the lower back and knee mechanics during box drop and prone to standing tasks." Ergonomics 59 (5):682-91. doi: 10.1080/00140139.2015.1081413.

Ramstrand, N., R. Zugner, L. B. Larsen, and R. Tranberg. 2016. "Evaluation of Load Carriage Systems used by Active Duty Police Officers: Relative Effects on Walking Patterns and Perceived Comfort." Applied Ergonomics 53 Pt A:36-43. doi: 10.1016/j.apergo.2015.08.007.

Raya, M. A., R. S. Gailey, I. A. Gaunaurd, D. M. Jayne, S. M. Campbell, E. Gagne, P. G. Manrique, D. G. Muller, and C. Tucker. 2013. "Comparison of three agility tests with male servicemembers: Edgren Side Step Test, T-Test, and Illinois Agility Test." Journal of Rehabilitation Research and Development 50 (7):95160. doi: 10.1682/JRRD.2012.05.0096. 
Schram, B., B. Hinton, R. Orr, R. Pope, and G. Norris. 2018. "The Perceived Effects and Comfort of Various Body Armour Systems on Police Officers while Performing Occupational Tasks." Annals of Occupational and Environmental Medicine 30 (15).

Schram, B., R. Orr, R. Pope, B. Hinton, and G. Norris. 2018. "Comparing the effects of different body armor systems on the occupational performance of police officers." International Journal of Environmental Research and Public Health 15 (5). doi: 10.3390/ijerph15050893.

Sell, T. C., Y. Chu, J. P. Abt, T. Nagai, J. Deluzio, M. A. McGrail, R. S. Rowe, and S. M. Lephart. 2010. "Minimal Additional Weight of Combat Equipment Alters Air Assault Soldiers' Landing Biomechanics." Military Medicine 175 (1):41-7. doi: 10.7205/MILMED-D-09-00066.

Strating, M., R. H. Bakker, G. J. Dijkstra, K. A. P. M. Lemmink, and J. W. Groothoff. 2010. "A job-related fitness test for the Dutch police." Occupational Medicine 60 (4):255-60. doi: 10.1093/occmed/kqq060.

Tomes, C., R. M. Orr, and R. Pope. 2017. "The impact of body armor on physical performance of law enforcement personnel: a systematic review." Annals of Occupational and Evnironmental Medicine 29 (14). doi: 10.1186/s40557-0170169-9.

Treloar, A. K., and D. C. Billing. 2011. "Effect of load carriage on performance of an explosive, anaerobic military task." Military Medicine $176(9): 1027-31$. 
Table 1: Demographics of study participants. Results are expressed as mean $\pm \mathrm{SD}$ (range).

\begin{tabular}{ccc}
\hline Measure & Females & Males \\
\hline Number & 5 & 6 \\
\hline Age (yrs) & $27 \pm 3(24-32)$ & $40 \pm 8(29-51)$ \\
\hline Weight $(\mathrm{kg})$ & $68 \pm 18(54-99)$ & $83 \pm 20(56-101)$ \\
\hline Height $(\mathrm{cm})$ & $164 \pm 7(155-170)$ & $177 \pm 9(162-187)$ \\
\hline Months of Service (mo) & $78 \pm 12(68-98)$ & $92 \pm 9(80-102)$ \\
\hline
\end{tabular}

Table 2: Daily Schedule across the four days of testing.

\begin{tabular}{ll}
\hline Time & Activity \\
\hline 0800 & Morning Brief - allocation of armour and equipment issue \\
0900 & Vertical Jump \\
1130 & Illinois Agility Test and $20 \mathrm{~m}$ sprint \\
1300 & Vertical Jump \\
1330 & Counter Movement Jump \\
1600 & Debrief \\
\hline
\end{tabular}

Table 3. Mean weight \pm SD and ranges for each type of ILAV and normal station wear $(\mathrm{N})$

\begin{tabular}{cccc}
\hline ILAV type $(\mathrm{A}-\mathrm{C}) \&$ & ILAVWeight & Duty load & Total load including officer weight \\
Normal station wear $(\mathrm{N})$ & $(\mathrm{kg})$ & Complete $(\mathrm{kg})$ & $(\mathrm{kg})$ \\
\hline $\mathrm{A}$ & $4.12 \pm 0.65^{*}$ & $11.53 \pm 0.77 \dagger$ & $88.03 \pm 20.49$ \\
$\mathrm{~B}$ & $3.54 \pm 0.70^{*}$ & $11.01 \pm 1.01 \dagger$ & $87.51 \pm 20.60$ \\
$\mathrm{C}$ & $3.24 \pm 0.48^{*}$ & $10.77 \pm 1.16 \dagger$ & $87.27 \pm 20.66$ \\
$\mathrm{~N}$ & $\mathrm{NA}$ & $8.69 \pm 0.68$ & $85.19 \pm 20.24$
\end{tabular}

\footnotetext{
* Significantly different $(\mathrm{p}<.05)$ from normal station wear: ${ }^{*}$ Significantly different $(\mathrm{p}<.001)$ from normal station wear
} 
Table 4: Results of the assessments by ILAV type. ( $\mathrm{N}=$ normal station wear) Results expressed as mean \pm SD. ${ }^{a}=$ significantly less than ILAV A, ${ }^{\mathrm{b}}=$ significantly less than ILAV B ${ }^{\mathrm{c}}=$ significantly less than ILAV C.

\begin{tabular}{|c|c|c|c|c|c|}
\hline & ILAV A & ILAV B & ILAV C & $\mathrm{N}$ & $p$ value \\
\hline Vertical Jump AM (cm) & $33.81 \pm 7.06$ & $32.82 \pm 6.69$ & $34.18 \pm 6.72$ & $34.55 \pm 7.24$ & 0.086 \\
\hline Vertical Jump PM (cm) & $34.91 \pm 7.50$ & $35.27 \pm 7.09$ & $36.00 \pm 9.30$ & $36.91 \pm 8.34$ & 0.663 \\
\hline Agility (s) & $21.11 \pm 2.12$ & $21.11 \pm 1.91$ & $20.61 \pm 2.04$ & $21.04 \pm 2.57$ & 0.428 \\
\hline 20m Sprint (s) & $4.02 \pm 0.30$ & $3.98 \pm 0.33$ & $3.97 \pm 0.48$ & $3.95 \pm 0.36$ & 0.879 \\
\hline CMJ Mean Force (N) & $867 \pm 200$ & $863 \pm 200$ & $859 \pm 199$ & $840 \pm 197^{\mathrm{a}, \mathrm{b}, \mathrm{c}}$ & 0.001 \\
\hline CMJ Peak Force $(\mathrm{N})$ & $3649.70 \pm 1120.74$ & $3704.40 \pm 1189.79$ & $3493.75 \pm 1077.35$ & $3460.49 \pm 1407.79$ & 0.905 \\
\hline CMJ Peak Jump (m) & $0.32 \pm 0.11$ & $0.35 \pm 0.13$ & $0.34 \pm 0.12$ & & 0.561 \\
\hline CMJ Peak Velocity $(\mathrm{m} / \mathrm{s})$ & $1.49 \pm 0.23$ & $1.53 \pm 0.22$ & $1.50 \pm 0.27$ & $1.49 \pm 0.25$ & 0.756 \\
\hline CMJ Peak Power (W) & $2401.85 \pm 943.79$ & $2423.47 \pm 918.45$ & $2379.26 \pm 976$ & $2379.60 \pm 983.36$ & 0.893 \\
\hline
\end{tabular}




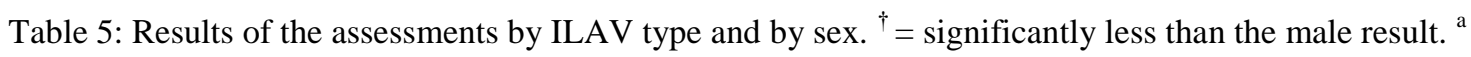
$=$ significantly less than ILAV A, ${ }^{\mathrm{b}}=$ significantly less than ILAV B ${ }^{\mathrm{c}}=$ Significantly less than ILAV C

\begin{tabular}{|c|c|c|c|c|c|}
\hline & ILAV A & ILAV B & ILAV C & $\mathrm{N}$ & $p$ value \\
\hline Male Vertical Jump AM (cm) & $38.67 \pm 4.76$ & $37.50 \pm 3.93$ & $38.33 \pm 5.13$ & $39.67 \pm 4.55$ & .232 \\
\hline Female Vertical Jump AM (cm) & $28.00 \pm 4.36^{\dagger}$ & $28.80 \pm 4.15^{\dagger}$ & $29.20 \pm 4.81^{\dagger}$ & $28.40 \pm 4.34^{\dagger}$ & .208 \\
\hline Male Vertical Jump PM (cm) & $40.00 \pm 5.51$ & $40.00 \pm 4.97$ & $42.67 \pm 6.95$ & $40.00 \pm 9.38$ & .616 \\
\hline Female Vertical Jump PM (cm) & $28.80 \pm 4.15^{\dagger}$ & $29.60 \pm 4.56^{\dagger}$ & $28.00 \pm 3.00^{\dagger}$ & $33.20 \pm 5.67$ & .094 \\
\hline Male Agility (s) & $19.55 \pm 1.17$ & $19.77 \pm 0.99$ & $19.34 \pm 1.26$ & $19.59 \pm 1.79$ & .900 \\
\hline Female Agility (s) & $22.98 \pm 1.25^{\dagger}$ & $22.72 \pm 1.41^{\dagger}$ & $22.13 \pm 1.76^{\dagger}$ & $22.77 \pm 2.36^{\dagger}$ & .421 \\
\hline Male $20 \mathrm{~m}$ Sprint (s) & $3.86 \pm 0.15$ & $3.82 \pm 0.19$ & $3.67 \pm 0.14^{\mathrm{a}}$ & & .033 \\
\hline Female $20 \mathrm{~m}$ Sprint (s) & $4.21 \pm 0.34^{\dagger}$ & $4.17 \pm 0.39$ & $4.33 \pm 0.49^{\dagger}$ & & .799 \\
\hline Male CMJ Mean Force (N) & $935.30 \pm 201.45$ & $931.45 \pm 204.96$ & $927.55 \pm 198.95$ & $906.52 \pm 200.84^{\mathrm{a}, \mathrm{b}, \mathrm{c}}$ & $<.001$ \\
\hline Female CMJ Mean Force (N) & $784.80 \pm 185.08$ & $780.50 \pm 178.38$ & $776.56 \pm 184.02$ & $759.76 \pm 179.79^{\mathrm{a}, \mathrm{b}}$ & $<.001$ \\
\hline Male CMJ Peak Force (N) & $3946.98 \pm 934.24$ & $4439.03 \pm 1013.14$ & $4061.32 \pm 834.57$ & $3980.33 \pm 1615.16$ & .828 \\
\hline Female CMJ Peak Force (N) & $3292.96 \pm 1325.69$ & $2822.84 \pm 689.17^{\dagger}$ & $88 \pm 984.08^{\dagger}$ & $2836.68 \pm 899.45$ & .744 \\
\hline Male CMJ Peak Jump (m) & $0.36 \pm 0.11$ & 0 & $0.40 \pm 0.13$ & $0.42 \pm 0.17$ & .664 \\
\hline Female CMJ Peak Jump (m) & $0.26 \pm 0.07$ & & $0.26 \pm 0.04^{\dagger}$ & $0.26 \pm 0.04$ & .542 \\
\hline Male CMJ Peak Velocity $(\mathrm{m} / \mathrm{s})$ & $1.60 \pm 0.21$ & & $1.62 \pm 0.30$ & $1.64 \pm 0.24$ & .933 \\
\hline $\begin{array}{l}\text { Female CMJ Peak Velocity } \\
(\mathrm{m} / \mathrm{s})\end{array}$ & $1.34 \pm 0.17$ & & $1.34 \pm 0.11$ & $1.31 \pm 0.07^{\dagger}$ & .561 \\
\hline Male CMJ Peak Power (W) & 2889.23 & $2905.53 \pm 935.18$ & $2899.28 \pm 1027.69$ & $2910.53 \pm 1035.88$ & .998 \\
\hline Female CMJ Peak Power (W) & $1817.20 \pm 511.62$ & $1845.00 \pm 498.83$ & $1755.24 \pm 415.98^{\dagger}$ & $1742.48 \pm 382.03^{\dagger}$ & .478 \\
\hline
\end{tabular}

